\title{
Lógicas do Sistema Mundo Moderno Colonial e violências contra os Povos Indígenas no Brasil
}

\section{Lógicas del Sistema Mundo Moderno/Colonial y violencias contra los Pueblos Indígenas en Brasil}

\author{
Ana Catarina Zema de Resende \\ Universidade de Brasília - UnB \\ e-mail: ana.zema@gmail.com \\ Sandra Márcia Nascimento \\ Universidade de Brasília - UnB \\ e-mail: sandranascimento2015@gmail.com
}

\begin{abstract}
Resumo
A constituição do Sistema Mundo Moderno/Colonial impôs aos povos indígenas um lugar de subordinação político-jurídica e social inegável. A análise desse Sistema e seus impactos sobre a vida de milhares de indígenas convida a pensar a trajetória de luta e de resistência dos Povos Indígenas no Brasil em uma longa duração. O propósito deste artigo é mostrar, na perspectiva decolonial, que existe uma relação intrínseca entre as lógicas do Sistema Mundo Moderno/Colonial e as diferentes formas que a práxis de dominação/violência contra os Povos Indígenas assume ao longo do processo de expansão e consolidação da supremacia cultural do ocidente no marco global das relações de poder. A ideia é apresentar uma proposta de reflexão teórica para o enquadramento da violência histórica cometida contra os povos indígenas no Brasil a partir do diálogo com a perspectiva de análise do Sistema Mundo Moderno/Colonial.
\end{abstract}

Palavras-chave: sistema mundo, decolonial, povos indígenas, violências.

\section{Resumen}

La constitución del Sistema Mundo Moderno/Colonial impuso a los pueblos indígenas un lugar de subordinación político-jurídica y social innegable. El análisis de ese Sistema y sus impactos sobre la vida de miles de indígenas invita a pensar la trayectoria de lucha y de resistencia de los Pueblos Indígenas en Brasil en una larga duración. El propósito de este artículo es mostrar, en la perspectiva decolonial, que existe una relación intrínseca entre las lógicas del Sistema Mundo Moderno / Colonial y las diferentes formas que la praxis de dominación / violencia contra los Pueblos Indígenas asume a lo largo del proceso de expansión y consolidación de la supremacía cultural del occidente en el marco global de las relaciones de poder. La idea es presentar una propuesta de reflexión teórica para el encuadramiento de la violencia histórica cometida contra los pueblos indígenas en Brasil a partir del diálogo con la perspectiva de análisis del Sistema Mundo Moderno / Colonial.

Palabras clave: sistema mundo, decolonial, pueblos indígenas, violencias. 


\section{Introdução}

A análise do Sistema-Mundo Moderno/Colonial convida a pensar a história de resistência e luta dos povos indígenas no Brasil por direitos desde a colônia até à conjuntura da formação dos Estados-nacionais, persistindo contemporaneamente ante as múltiplas violências sofridas, em uma "longa duração" (BRAUDEL, 1949). A longa duração permite discernir continuidades e rupturas em um tempo lento, focando o olhar nas tendências estruturais do caminhar das sociedades ao invés de focar 0 olhar nos epifenômenos e nos acontecimentos históricos superficiais.

A partir do enfoque decolonial, observa-se que o capitalismo global contemporâneo ressignificou as práticas de exclusão provocadas pela hierarquização racial/étnica implantadas pelo Sistema-Mundo Moderno/Colonial e que as estruturas de longa duração formadas a partir do século XVI no Brasil continuam desempenhando um papel importante no presente. Partimos, neste trabalho, do pressuposto de que, mesmo após quase duzentos anos de superação da condição colonial e mesmo com as mudanças paradigmáticas que a Constituição Federal de 1988 trouxe, a questão dos direitos dos povos indígenas ainda segue uma trajetória de acumulação de violências historicamente determinantes da vulnerabilidade desses povos.

O aporte decolonial propõe uma interpretação e explicação da atualidade em termos de continuidades, ao mesmo tempo em que postula que a emancipação dos dominados é condicionada pela ruptura com essa continuidade ou, pelo menos, por sua renegociação. Por este aspecto, demonstraremos que a violência contra os povos indígenas assume diferentes formas ao longo do processo de expansão e consolidação do sistema-mundo capitalista e como os processos históricos de constituição de um marco global de relações de poder significaram para os povos indígenas uma condição de negação sistemática de sua identidade e de seus direitos. De fato, eles foram os primeiros atores que, no momento de constituição do Sistema-Mundo Moderno/Colonial, viram-se aprisionados por esse sistema, cuja violência é inegável.

Nos últimos anos, documentos e testemunhos se acumularam revelando um panorama sombrio e persistente das situações de violência contra os povos indígenas do Brasil. As violações mais notórias são aquelas que atentam contra os direitos civis, políticos e culturais, impactando a própria existência identitária destes povos. Mas, sem dúvida, as mais persistentes são as violações ao direito de propriedade comunitária e à autodeterminação. 
Para a compreensão do cenário atual e do contexto histórico que desencadeia a lógica da dominação cultural dos povos indígenas no Brasil, iremos abordar, no primeiro momento, as linhas gerais da proposta teórica de análise do Sistema Mundo como elaborada por Immanuel Wallerstein. Em seguida, apresentamos as reelaborações dessa teoria pelos pensadores decoloniais, particularmente Walter Mignolo e Enrique Dussel, que adotam o Sistema Mundo como unidade de análise em seus estudos. Em um terceiro momento, mostramos como as modalidades de violências, em particular a violência patrimonial e identitária, que os povos indígenas sofreram têm uma historicidade específica relacionada com as estratégias adotadas pelos Estados nos diferentes momentos de sua inserção no Sistema Mundo Moderno/Colonial e em função da posição que vêm a ocupar nesse sistema. O propósito deste artigo é mostrar, na perspectiva decolonial, que existe uma relação intrínseca entre as lógicas do Sistema Mundo Moderno/Colonial e as diferentes formas que a práxis de dominação/violência contra os Povos Indígenas assume ao longo do processo de expansão e consolidação da supremacia cultural do ocidente no marco global das relações de poder, em particular no âmbito dos direitos territoriais. Objetiva-se trazer contribuições para a discussão teórica acerca da relação entre as lógicas do Sistema Mundo Moderno/Colonial e as violências que esse sistema impôs aos povos indígenas, no cenário brasileiro, no entanto, não serão abordados aqui, em detalhe, os processos históricos específicos da exclusão patrimonial e identitária dos povos indígenas, uma vez que este trabalho tem como ponto de partida a contemporânea situação de exclusão a que os povos indígenas estão submetidos. Este artigo traça uma trajetória reversa do plano eurocentrado de subordinação dos índios, pensando as conexões entre passado e presente.

\section{A Teoria do Sistema Mundo: categorização ante o eurocentrismo}

A teoria do Sistema Mundo é uma perspectiva macrossociológica que procura explicar a dinâmica da economia-mundo capitalista como um "sistema social total". Immanuel Wallerstein foi quem primeiro articulou a análise do Sistema Mundo em 1974 no seu livro The rise and future demise of the World Capitalist System: concepts for comparative analysis. Em 1976, ele publicou sua obra seminal, The Modern World System I: Capitalist Agriculture and the Origins of the European World-Economy in the Sixtenth Century, onde apresenta seu enfoque histórico do capitalismo que se tornaria sua grande contribuição para o pensamento sociológico e histórico (MARTÍNEZ-VEGA, 2003). Em sua teoria do Sistema Mundo, Wallerstein propõe uma análise do capitalismo como sistema mundial e sustenta que, 
os processos históricos de constituição do capitalismo como marco global de relações de poder são fundamentais para a compreensão da nossa história e do nosso presente.

De acordo com Wallerstein (2006, p. x), para a análise dos fenômenos recentes, deve-se primeiro levar em conta que eles fazem parte de um cenário maior. Parte da dificuldade que temos em explicar esses fenômenos vem do hábito de estudá-los em compartimentos estanques que chamamos de política, economia, estrutura social, cultura, sem lembrar que esses compartimentos são parte de nossa imaginação. É preciso então considerar que esses fenômenos estão estreitamente entrelaçados. Wallerstein sustenta que: a) "os compartimentos estanques de análise - o que as universidades chamam de disciplinas - são um obstáculo e não uma ajuda para a compreensão do mundo"; b) a realidade em que vivemos e que determina quais são nossas opiniões não são as dos múltiplos Estados nacionais, senão as de algo maior que chama de Sistema Mundo; c) o Sistema Mundo tem contado com muitas instituições - Estados e sistemas interestatais, companhias de produção, marcas, classes, grupos de identificação de todo tipo - e estas instituições formam uma matriz que permite o sistema operar, mas que, ao mesmo tempo, estimula tanto os conflitos quanto as contradições que permeiam o sistema e d) esse sistema é uma criação social, com uma história com origens que devem ser explicadas, mecanismos presentes que devem ser delineados e cuja inevitável crise deve ser advertida (2006, p. xi - xii).

Wallerstein escreveu uma obra em três volumes (e está produzindo o quarto) na qual apresenta sua perspectiva da história global do Sistema Mundo capitalista, desde suas origens até a atualidade. Na sua proposta de apreender a história do capitalismo moderno reconstruindo teoricamente suas estruturas mais essenciais, Wallerstein apresenta três teses principais ou propostas metodológicas que acabam por mostrar a originalidade de seu pensamento com relação àqueles pensadores que também analisaram 0 capitalismo como um "problema global" como Karl Marx, Max Weber, Karl Polanyi, Fernand Braudel, entre outros. Em primeiro lugar, a unidade de análise pertinente, necessária para analisar e investigar os fenômenos, sucessos e processos que aconteceram ao longo dessa história secular do capitalismo. Em segundo lugar, a estrutura hierárquica interna desse sistema e, em terceiro lugar, as "dinâmicas e curvas de transformação que marcam o ritmo desse sistema histórico capitalista" (ROJAS, 2007, p. 21).

A unidade de análise pertinente não pode, segundo Wallerstein, ser outra que a do Sistema Mundo sempre considerado em sua totalidade, ou seja, em sua mais vasta dimensão geográfica, primeiro semiplanetária e, depois 
planetária. Em lugar dos Estados nacionais - estandarte de análise dos historiadores, economistas, cientistas políticos e sociólogos - como objetos de estudo, Wallerstein propõe os "sistemas históricos" que, até o momento, existiram em três variantes: "minissistemas" e "sistema-mundo" de dois tipos: "economia-mundo e império-mundo" (2006, p. 20). A ideia não é fazer referência a sistemas, economias ou impérios de todo o mundo, mas mostrar que sistemas, economias e impérios são um mundo. O Sistema Mundo corresponde assim a uma "zona espaço-temporal que atravessa múltiplas unidades políticas e culturais" e que "representa uma zona integrada de atividade e instituições que obedecem a certas regras sistêmicas" (WALLERSTEIN, 2006, p. 20).

De acordo com Wallerstein, um Sistema Mundo é um sistema social e histórico complexo por consistir nas intersecções de múltiplas estruturas. Trata-se de um "sistema que tem uma dinâmica própria que produz e reproduz relações entre processos e estruturas" (1979, p. 489).

O caráter orgânico do Sistema Mundo que garante a unidade entre os processos e as estruturas está, segundo Wallerstein, na divisão do trabalho que é capaz de ultrapassar as fronteiras nacionais e políticas, locais e culturais. Essa divisão extensiva do trabalho não é meramente funcional ou ocupacional, mas é geográfica, ou seja, não é distribuída uniformemente em toda a extensão do Sistema Mundo. Isso acontece, em parte, como consequência de fatores ecológicos, mas se dá também em função da organização social do trabalho que "legitima a capacidade de certos grupos dentro do sistema de explorar o trabalho de outros, isto é, de receber uma parte maior do excedente" (1979, p. 492). No capitalismo histórico, os interesses de acumulação organizaram a divisão mundial do trabalho. As trocas comerciais entre os Estados a nível mundial participam da organização dessa divisão do trabalho de acordo com os interesses capitalistas de lucro e a incessante acumulação de capital e, portanto, o comércio internacional não deve ser compreendido apenas como atividade que une economias nacionais autônomas. A ampla abrangência espacial e sua capacidade de se autorreproduzir é que fazem desse sistema "um mundo", na medida que ultrapassa a jurisdição territorial de um Estado nacional. Um Sistema Mundo é, portanto, um sistema social que funciona com uma divisão de trabalho que, por sua vez, garante a reprodução desse "mundo".

A estrutura hierárquica do capitalismo histórico é tripartida: centro, periferia e semiperiferia. Essa estrutura, profundamente desigual e assimétrica, divide o planeta em um pequeno número de países ou zonas muito ricas que conformam o centro, junto com um também pequeno 
número de países que formam uma zona intermediária, a semiperiferia, que detém uma riqueza moderada, ao lado de um grande número de países que constituem a zona pobre e explorada que suporta ou sustenta tanto a semiperiferia quanto a periferia do sistema (ROJAS, 2007, p. 24).

A terceira tese central na teoria de Wallerstein diz respeito às distintas dinâmicas que, nos diversos tempos históricos, vão ritmando o devir histórico do Sistema Mundo capitalista. Dinâmicas diferenciadas, mas profundamente entrelaçadas que abarcam, no plano das conjunturas históricas, o tempo médio braudeliano, os ciclos de Kondratiev e, no plano da longa duração, primeiro, as mudanças importantes que trouxeram os distintos e sobrepostos "longos séculos" da história capitalista com seus movimentos de expansão e consolidação e, depois, a dinâmica global dos sucessivos ciclos hegemônicos da modernidade capitalista (ROJAS, 2007, p. 26).

A abordagem do moderno sistema mundial apresenta um arcabouço teórico-analítico que possibilita tanto a explicação da acumulação primitiva e sua apropriação desigual na formação da economia-mundo capitalista, quanto a acumulação do excedente que se dá de forma diferenciada nos ciclos de expansão capitalista, inclusive em sua fase contemporânea.

Por volta de 1500, uma economia particular teria surgido fornecendo um quadro para o pleno desenvolvimento do modo de produção capitalista. Uma vez consolidada e seguindo uma lógica interna, essa economia-mundo vai se expandir pelo espaço integrando os impérios-mundo assim como os minissistemas. No final do século XIX, a economia-mundo capitalista se expandiu pela totalidade do planeta. A partir daí, pela primeira vez na história, passou a existir apenas um único sistema histórico.

A economia-mundo que garante a integração do sistema não é uma entidade política central, e sim a divisão do trabalho articulada através do mercado que coloca duas ou mais regiões, cultural e politicamente distintas, em uma relação de interdependência econômica. Trata-se de um sistema interestatal, cuja unidade econômica é dada pela divisão do trabalho e não por uma unidade política central. "O moderno sistemamundo é, por definição do autor, uma economia-mundo capitalista combinada com múltiplos Estados nacionais, que, juntos, formam o sistema interestatal" (ARIENTI; FILOMENO, 2007, p. 105).

A explicação da divisão do trabalho no seio do Sistema Mundo capitalista entre centro e periferia permite averiguar os mecanismos de apropriação do excedente na escala mundial para a burguesia por meio de uma troca 
desigual materializada por múltiplas cadeias mercantis que garantem o controle sobre os trabalhadores e o monopólio da produção.

O Sistema Mundo, da forma como Immanuel Wallerstein o pensou, implica uma organização da economia dominada por um ou mais centros que impõe suas lógicas às periferias. Esse sistema mundo é um sistema de lugares dominantes e dominados e das relações entre eles. O sistema interestatal que acompanha a economia-mundo capitalista é continuamente conduzido por um Estado hegemônico.

Esse sistema cada vez mais integrado nasceu com as invasões dos territórios indígenas no final do século $\mathrm{XV}$, ao mesmo tempo em que $\mathrm{O}$ capitalismo mercantil europeu começava a expandir suas relações comerciais à escala mundial. A emergência deste sistema está ligada a uma série de fenômenos relacionados entre si: 1) o capitalismo como sistema econômico; 2) o florescimento da ciência e tecnologia associado às necessidades do capitalismo; 3) a secularização da vida social; 4) o sistema de Estados e 5) o universalismo que é uma ideia de acordo com a qual todos os conhecimentos, valores e direitos de uma sociedade, neste caso os europeus, pertencem a todas as pessoas (RESTREPO; ROJAS, 2010, pp. 7172). O resultado da consolidação desse Sistema Mundo moderno foi o lugar de centro do poder que ganhou a Europa no contexto mundial nos séculos seguintes.

Em seu livro O capitalismo histórico, originalmente publicado em 1983, Wallerstein mostrou como universalismo e racismo constituem os dois pilares ideológicos do capitalismo histórico. Com relação ao universalismo, Wallerstein explica que se trata de crenças sobre "o que se pode conhecer e como se pode conhecer". A essência dessa tese é que existem enunciados gerais significativos sobre o mundo que são verdadeiros universal e permanentemente (WALLERSTEIN, 1983 apud RESTREPO; ROJAS, 2010, p. 76). O racismo foi a "justificação ideológica da hierarquização da força de trabalho e da distribuição extremamente desigual de suas recompensas" (WALLERSTEIN, 1983 apud RESTREPO; ROJAS, 2010, p. 75).

\section{O Sistema Mundo Moderno/Colonial: perspectiva histórica e imbricações étnico/raciais}

A perspectiva totalizante e crítica da história e da situação atual do moderno capitalismo de Wallerstein tem influenciado alguns pensadores da decolonialidade a refletirem sobre os processos históricos de constituição de um marco global de relações de poder que significou para os povos indígenas das Américas uma condição de subordinação. De acordo 
com Eduardo Restrepo e Axel Rojas, a análise do Sistema Mundo de Wallerstein é uma das "teorias nodais para compreender a inflexão decolonial, ainda que essa contribuição não tenha tido o mesmo peso para todos os participantes da coletividade de argumentação" e tenha recebido algumas críticas de alguns deles (2010, p. 69).

Uma das críticas que Walter Mignolo faz à teoria do Sistema Mundo de Wallerstein é que esta deixou de considerar que a modernidade nasce junto com a colonialidade, constituindo um único processo. Para os pensadores decoloniais, a colonialidade é o lado obscuro da modernidade. Mignolo propõe, então, a noção de Sistema Mundo Moderno/Colonial para enfatizar essa concomitância entre colonialidade e modernidade e mostrar que ambas devem ser pensadas a partir de uma perspectiva de Sistema Mundo. Assim o filósofo argentino explica essa concomitância:

Mientras que por un lado se cantan, y se cantaron desde siempre, loas a la cristianización, a la civilización, al progreso, a la modernización, al desarrollo (la cara de la modernidad), por otro se oculta que para que todo ello ocurra es necesario la violencia, la barbarie, el atraso, la "invención de la tradición", el subdesarrollo (la cara de la colonialidad). Desde siempre, es decir, desde el siglo XVI, la modernidad y la colonialidad van juntas; no hay modernidad sin colonialidad aunque los discursos siempre pronunciados desde la perspectiva de la modernidad (...) presentan a la colonialidad no como un fenómeno constitutivo sino derivativo: la gran mentira (o quizá el gran error y la gran ignorancia, si se prefiere) es hacer creer (o creer) que la modernidad superará la colonialidad cuando, en verdad, la modernidad necesita de la colonialidad para instalarse, construirse y subsistir. No hubo, no hay y no habrá modernidad sin colonialidad (MIGNOLO, 2003, pp. 34-35).

A partir dessas considerações, percebe-se que a diferença entre a noção de Sistema Mundo Moderno de Wallerstein e a noção de Sistema Mundo Moderno/Colonial de Mignolo está na ênfase que este último coloca na colonialidade. O adjetivo "moderno" indica na noção de Wallerstein contemporaneidade, enquanto que, na expressão de Mignolo, "a ênfase na colonialidade transforma a própria noção de modernidade" (RESTREPO; ROJAS, 2010, p. 79).

Enrique Dussel também faz uma leitura particular da teoria do Sistema Mundo de Wallerstein. Primeiro, ele questiona a ideia da sucessão linear da "história universal" e mostra que a Europa ocupou um lugar de periferia, em 
relação ao mundo muçulmano e chinês, até o século XVIII. Em seguida, ele indaga a concepção intra-europeia de modernidade, ou seja, a concepção segundo a qual a modernidade teria surgido como um fenômeno exclusivamente europeu. Finalmente, Dussel mostra que o papel da América nesse processo foi constitutivo; mesmo que se afirme que a modernidade nasceu na Europa, isso só foi possível por causa da profunda confrontação produzida pelos europeus no momento do mal chamado "descobrimento" da América:

1492, según nuestra tesis central, es la fecha del "nacimiento" de la Modernidad; aunque su gestación -como el feto-lleve un tiempo de crecimiento intrauterino. La Modernidad se originó en las ciudades europeas medievales, libres, centros de enorme creatividad. Pero "nació" cuando Europa pudo confrontarse con "el Otro" y controlarlo, vencerlo, violentarlo; cuando pudo definirse como un "ego" descubridor, conquistador, colonizador de la Alteridad constitutiva de la misma Modernidad. De todas maneras, ese Otro no fue "des-cubierto" como Otro, sino que fue "en-cubierto" como "lo Mismo" que Europa ya era desde siempre. De manera que 1492 será el momento del "nacimiento" de la Modernidad como concepto, el momento concreto del "origen" de un "mito" de violencia sacrificial muy particular $y$, al mismo tiempo, un proceso de "en-cubrimiento" de lo no-europeo (DUSSEL, 1994, p. 7-8).

Para Dussel, a conquista do continente americano não significou apenas a possibilidade da conversão do capital em sistema capitalista global graças ao fluxo de metais preciosos, mas significou também, simultaneamente, o aparecimento de uma primeira modernidade que tem seu epicentro na Europa do Sul e sua periferia na América. Essa primeira modernidade, ao mesmo tempo, centrada na Europa e global, proporcionou uma gigantesca acumulação primitiva predatória e o aparecimento de uma nova "geocultura" colonial com formas de subjetivação coletiva originais. A lógica particular que propicia a emergência de subjetividades colonializadas tem como principal característica a negação de sua alteridade. Como explica Dussel, "El 'índio' no fue descubierto como Otro, sino como 'lo Mismo' ya conocido (el asiático) y sólo re-conocido (negado entonces como Otro): 'en-cubierto' (1994, p. 31).

\section{Memória social da dominação e violências contra os povos indígenas}

O que aconteceu com o chamado "descobrimento" da América foi, antes de qualquer coisa, o apagamento de sua singular e irredutível alteridade 
(CLAVERO, 2001). Antes do suposto desconhecido poder revelar-se, predominou a tendência em "en-cobrir" e domesticar a diferença com termos e princípios inteligíveis para os europeus. Essa tendência não se limitou a "digressões teológicas e epistêmicas, mas se articulou com toda uma série de práticas de dominação por meio das quais assujeitaram, pela força e pela conversão, as populações colonizadas e foi sedimentada a subjetividade do colonizador" (RESTREPO; ROJAS, 2010, p. 81).

À crítica da modernidade como uma narrativa celebratória da emancipação pela razão, produzida pela "genialidade e excepcionalidade histórica dos europeus", Dussel (2000) acrescenta seu "lado obscuro ou irracionalidade imanente: o efeito da 'violência sacrificial' e a 'falácia eurocêntrica' do 'mito da modernidade". O "mito da modernidade" como processo racional de saída da humanidade de um estado de imaturidade regional, acoberta o processo irracional e de brutal violência sobre os povos indígenas que justificou a dominação. A violência da dominação por trás do "mito da modernidade" é, de acordo com Dussel, interpretada como um "ato inevitável e com um sentido quase ritual". O "bárbaro", para o moderno europeu, é culpado por opor-se ao processo civilizador. A "Modernidade" pode apresentar-se assim, não apenas como inocente, mas como emancipadora dessa "culpa". Os sofrimentos ou sacrifícios são vistos como inevitáveis no processo de "'modernização' dos outros povos 'atrasados' (imaturos), das outras raças 'escravizáveis', do outro sexo tido como frágil, etc." (DUSSEL, 2000, p. 49).

Os povos indígenas viram-se privados de suas identidades culturais por meio de uma operação discursiva que homogeneizou e essencializou todos os povos indígenas ao designá-los por um referente identitário que se tornaria a marca duradoura de sua inferioridade social; eles foram chamados de índios (QUIJANO, 2000, p. 120). Além de terem suas identidades culturais "encobertas", foram desapossuidos de suas terras e meios de sobrevivência e, no momento de constituição desse Sistema Mundo Moderno/Colonial, viram-se aprisionados por esse sistema a condições de subordinação e a um processo violento de dominação.

Nesse ponto, interrogamo-nos sobre qual o lugar que os povos indígenas ocuparam e ocupam no Sistema Mundo Moderno/Colonial? De acordo com a teoria do Sistema Mundo Moderno/Colonial, percebe-se que esse lugar é marcado pela violência, pela exclusão, pela negação de sua alteridade, pela expropriação de suas terras e por sua transformação em mão de obra barata ou reserva de mão de obra. Por essa perspectiva, quando já não era conveniente exterminá-los fisicamente, mas tão somente etnicamente, a 
estratégia da práxis estatal foi o controle sobre a territorialidade, promovendo a territorialização oficial forçada (SOUZA LIMA, 1987).

Considerando os quatro períodos da economia-mundo capitalista: capitalismo mercantilista, capitalismo industrial, fordismo e globalização; é possível identificar como as lógicas impostas pelo modelo de desenvolvimento econômico de cada fase produziram diferentes tipos de violência sobre os povos indígenas, desde o genocídio fundacional até as mais recentes formas de coerção legal e social.

No caso dos Povos Indígenas do Brasil, ao longo dos três séculos da Colônia, o tratamento dado ao índio foi reflexo do papel que queriam atribuir-lhes os portugueses com vistas à sobrevivência econômica da metrópole. Se considerado "amigo", os portugueses previam a sedentarização, a catequese e o trabalho; se considerado "inimigo", restava ao índio a escravidão. As duas formas de tratamento tinham, no final, um mesmo propósito: levar os índios à civilização ocidental por meio da conversão religiosa e do trabalho forçado. A legislação indigenista produzida durante esse período foi contraditória e cheia de ambiguidades. Muitas foram as leis, alvarás, regimentos e cartas régias que afirmavam expressa e categoricamente a liberdade e a soberania dos índios, as quais, contudo, abriam espaço para subterfúgios e recursos que acabavam por legitimar a escravidão, como as "guerras justas" e o "resgate" (RESENDE, 2014).

Independentemente da diversidade e multiplicidade de suas histórias, os povos indígenas foram subjugados pelas lógicas do Sistema Mundo Moderno/Colonial e reduzidos à categoria genérica de "índios" mediante processos de distinção a partir de valorações culturais, biológicas e linguísticas que serviram para marcar a diferença entre índios e brancos. Além disso, na sua primeira fase, chamada de pré-industrial, o capitalismo histórico dependeu da incorporação de vastos espaços e ocasionou os primeiros genocídios. Acrescenta-se a isso, o sistema de extermínio e de deslocamento forçado colocado em prática para o povoamento da colônia.

A religião cristã foi também elemento importante na subjugação dos povos indígenas desde o período colonial já que a justificativa era a conversão, como mais uma estratégia do processo colonial econômico A ocupação e o povoamento do território que hoje chamamos de Brasil deu início a um processo mais amplo de inserção dessa parte do globo à economia-mundo como periferia. O Brasil colonial foi organizado como uma empresa, resultante da aliança entre burguesia mercantil (inclusive a holandesa) e a nobreza, orientada desde o início para a produção de mercadorias de alto valor para a Europa. A ordenação territorial no Brasil foi acompanhada pela 
formação de uma estrutura social baseada na escravização dos indígenas e dos(as) negros(as). Enfim, a incorporação do Brasil ao Sistema Mundo Moderno/Colonial, a partir do século XVI, implicou no ajuste social, econômico e político fundado na violência contra os povos indígenas (RESENDE, 2014).

No Império, surgem novos questionamentos sobre a humanidade dos índios e sobre sua capacidade de evolução. Essas interrogações provinham de uma preocupação relacionada às políticas que deveriam ser adotadas para com aqueles que se mostravam refratários à expansão da fronteira econômica: extermínio ou educação? Guerra ou paz? Manuela Carneiro da Cunha aponta este panorama no cenário brasileiro desde o século XVIII até meados do século XIX, período do debate sobre "exterminar os índios 'bravos"' ou "civilizá-los" e incluí-los na sociedade política - solução em geral propugnada por estadistas e que supunha sua possível incorporação como mão de obra (1992, p. 134). Mas, na República, sob a influência dos positivistas, as guerras e a escravidão foram cedendo espaço para uma política de proteção motivadas por uma suposta condição de infantilidade dos indígenas (RESENDE, 2014).

No século XIX, a ideia de modernização pressupunha um avanço racional de um modelo civilizatório que pretendeu a homogeneização de todos e trouxe consigo uma série etnocentrismos e estigmas culturais que só reforçaram os preconceitos raciais e sociais. A procura de homogeneidade nacional foi pensada como condição da legitimidade e da segurança do Estado-nação em construção naquele momento e, em função dessa lógica, novas formas de violência contra os povos indígenas foram criadas. As políticas de homogeneização que surgiram juntamente com o EstadoNação são fundadas sobre uma violência que nega a diferença, a alteridade e impõem a integração forçada ao corpo nacional via religião, língua ou, mais amplamente, via cultura. $O$ sucesso dessas políticas é garantido pelos aparelhos de Estado que difundem e impõem línguas, religiões e modelos culturais (RESENDE, 2014).

A formação do Estado-Nacional (histórico) foi acompanhada por um processo de classificação e hierarquização que deu corpo a um conjunto de estereótipos que continuam sendo reproduzidos na atualidade. Nesse processo, os povos indígenas permaneceram socialmente discriminados em função do estatuto social que receberam dentro da lógica das hierarquias que as elites descendentes dos colonos retomaram do período colonial (RESENDE, 2014). 
Durante a maior parte do século $\mathrm{XX}$, prevaleceu a concepção assimilacionista nas políticas indigenistas do Brasil (SOUZA LIMA, 1987). Pensava-se que os índios acabariam por se integrar definitivamente à sociedade nacional. Na prática, os sucessivos governos tentaram, por diversas vezes, "emancipar" à força os índios. Todas as políticas e legislações adotadas visaram sempre à integração dos indígenas à "comunhão" nacional. Essa integração sempre foi vista como uma necessidade e um bem para eles. No começo, para que saíssem ou deixassem seu estado de selvageria (século XVI ao XIX) e, depois, para que superassem seu estado de infantilidade (século XIX e XX). Essa ideia de que ser índio era uma condição transitória prevaleceu até recentemente no Brasil (RESENDE, 2014).

Durante a ditadura militar e, particularmente, ao longo dos anos 1970, com a expansão do capitalismo internacional, o crescimento econômico e os chamados processos de modernização, que funcionaram junto a governos autoritários, os povos indígenas tiveram suas terras invadidas para a exploração dos recursos naturais ali existentes, como minérios e madeira, de modo a atender às demandas de uma nova economia globalizada. Nesse período, o Brasil buscava consolidar um modelo de capitalismo oligopolista, imposto aos países da América Latina como condição para sua inserção no mercado internacional. A violência imposta pelos governos militares para aniquilar os povos indígenas, com a utilização inclusive de instrumentais bélicos, teve grande repercussão nacional e internacional, fato que acabou contribuindo para o surgimento das primeiras frentes de resistência indígena. Ao mesmo tempo, as condições políticas favoreceram os grupos de pressão desenvolvimentistas. Grandes campanhas a favor da exploração dos recursos naturais da Amazônia foram lançadas em detrimento dos direitos indígenas (RESENDE, 2014).

No caso do Brasil, partindo da história de sua inserção no Sistema Mundo Moderno/Colonial, o crescimento da economia brasileira, desde o início, se deu através de uma impressionante capacidade de incorporar rapidamente novas terras. À medida que o país foi crescendo economicamente e novas fronteiras geográficas foram redefinidas à custa de milhares de vidas indígenas, a estrutura fundiária preestabelecida, que constituiu - e constitui - a base do poder dos grupos dominantes, não mudou. A grande propriedade rural brasileira, herdada do latifúndio escravista, foi o instrumento básico para manter a reprodução da força de trabalho em condições próximas à de subsistência (RESENDE, 2014).

A questão da expropriação territorial dos povos indígenas, assim como a política fundiária imbricada com as lógicas ocidentais de hegemonização 
cultural e étnica, colocou milhares de indígenas em condições de vulnerabilidade social, econômica e de restrições das possibilidades de convivência intercultural com a sociedade nacional. A política de terras não esteve, segundo Carneiro da Cunha (1992) dissociada da política do trabalho. Neste aspecto, a lógica do Sistema Mundo Moderno/Colonial se consolida com a estratégia do extermínio cultural/étnico pela despossessão territorial. A lógica moderno/colonial da "proteção da posse" ao indígena alinhada aos planos operativos dessa expropriação possessória executada no período anterior à Constituição de 1988, executada em múltiplas estratégias racializadas sob o controle da Agência Indigenista, a Fundação Nacional do Índio (FUNAI), sucessora do Serviço de Proteção ao Índio (SPI), consistiu no aspecto modelar da subordinação dos povos indígenas no Brasil (NASCIMENTO, 2016). A negativa do direito de propriedade comunitária e a configuração da forma jurídica da posse e do usufruto dos recursos naturais aos indígenas, não representou qualquer transformação no sistema então adotado ou das práticas anteriores a 1988, pois não incorporou o elemento de identidade étnico. Até mesmo o reconhecimento dos direitos territoriais pela posse apenas ficou condicionado à comprovação de tradicionalidade. E o que é tradicional só pode ser verificado por critérios que os produtos jurídicos estatais comunicam, definidos e/ou reatualizados de acordo com a mesma lógica moderno/colonial do modelo econômico que determina os conceitos e nomeia, arbitrariamente, o que é posse, propriedade e tradicionalidade.

Como mencionado em linhas anteriores, o limiar do século XX foi marcado pelo desafio da redefinição da ordem jurídica/política e econômica em meio ao contexto da crítica ao indianismo romântico, em uma sociedade política emergente cheia de patologias (SANTOS, 2006 apud NASCIMENTO, 2016). As incertezas quanto às novas institucionalidades acabaram por preservar, nos primeiros dez anos da Primeira República os aspectos das relações de poder modeladas na herança conservadora e racialista do Império. Predominou, nesta conjuntura, entre antropólogos e historiadores o sentimento de que as medidas estatais protecionistas eram a melhor opção, porém, não isenta o tempo ou seus atores de terem validado práticas colonialistas (SILVA, 2012 apud NASCIMENTO, 2016). Esse cenário levou a alterações jurídicas que sinalizam para o tratamento do indígena como destinatário dos serviços do Estado, tais como educação escolar e saúde, porém, o traço da integração não foi abandonado. A violência estatal toma forma e adquire potência para conservar a subordinação dos povos indígenas, principalmente, a partir de sua segregação espacial (em parques ou áreas de reservas), com deslocamentos forçados, que gerou a 
despossessão enquanto indígenas, de tudo que os constitui identitariamente, tradições, saberes e territórios.

A política indigenista de territorialização até a década de 1980 esteve orientada pela confluência entre sobrevivência física e sobrevivência étnica, no entanto, esta teria sido suprimida por aquela, em razão do destino final ser a assimilação (SOUZA LIMA apud NASCIMENTO, 2016).

Essa territorialização, enquanto processo que subordina os indígenas e seus territórios a certa estrutura colonial dos regimes administrativos estatizados (SILVA apud NASCIMENTO, 2016), por meio de medidas oficiais, a partir de 1988 entra em choque com a territorialização espontânea e autodeterminada (oposição à imposição oficial) que Nascimento (2016) denomina de espacialidade ou espacialização étnica/ancestral.

Significa que mesmo após a Constituição de 1988 não foram suficientemente reposicionados os lugares dos povos indígenas como plenos agentes sócio-políticos e jurídicos. Fato que se explica pela herança, ou pela memória social (CAHEN, 2002) supremacista europeia (lusohispânica) imperante nas dinâmicas do Sistema Mundo Moderno/Colonial. Não se trata, contudo, apenas de uma disputa de mesma etnicidade com a etnicidade oponente. A leitura política da identidade étnica, segundo sugere Cahen (1994), decorre do seu contexto, história e da cena étnica nos espaços ditos nacionais ou plurinacionais, nos quais se pode observar e identificar as condicionalidades do existir étnico e as interações com os planos raciais. Segundo Cahen (2002) a etnicidade é, nesse aspecto, sentida. Significa que no momento em que o sujeito a afirma e a vivencia, como um fazer político, ela se apresenta como situação estável. O seu campo de ocorrência é o da internalidade que, no entanto, dialoga com as externalidades, como sustenta Clastres (2003). Estes autores, juntamente com Cardoso de Oliveira, entendem, cada um à sua maneira, que as identidades possuem uma expressão política que não se dissocia do processo de sua conservação intrínseca em face de uma reconfiguração externa. Ocorre que o desenho de pensar o mundo sociopolítico e econômico que Wallerstein propõe, que é o ponto de partida da análise neste trabalho, contribui para entendermos essa imbricação entre etnicidade e a estrutura de dominação econômica, que está atrelada à conservação dos privilégios do grupo dominante, que identitariamente não precisa se reconfigurar. De acordo com Barth (2000) há intrínseca relação das conexões históricas com os processos de constituição dos grupos étnicos. Para seu pensamento, que se enquadra bem no contexto desta análise, "as distinções entre categorias étnicas não dependem da ausência de mobilidade, contato e informação, mas implicam efetivamente processos 
de exclusão e incorporação" que apesar das mudanças ao longo da história de vida individuais, estas distinções são mantidas (BARTH, 2000, p. 26).

Por este aspecto, observa-se que a semântica positivista, que prevalece nos sentidos de uma sociedade nacional branca, cria, manipula e impõe suas lógicas de dominação, para validar as práticas de negação do acesso à terra e aos recursos naturais aos povos indígenas.

A partir das redesignações terminológicas de "terra habitada", "terra ocupada", passando para "área indígena", depois renomeada para "colônia indígena", substituída por "parque", incluindo-se a categoria de "reserva" e, novamente nominada como "terra indígena" observa-se a tentativa de ocultar a lógica racializada da manutenção do indígena na posição de "não sujeito" dentro da história oficial. Há, por trás dessa armadilha semântica, elementos modulares da subordinação dos povos indígenas a partir dos interesses das elites políticas e econômicas (NASCIMENTO, 2016). Estas, de uma maneira ambígua, estão associadas, negativamente, à interação étnica/cultural. Significa dizer que o comportamento das elites econômicas, do Estado e das oligarquias que se constituem no influxo do Sistema Mundo Moderno Colonial, preservou o controle sobre a existência dos povos indígenas de maneira irrevogável, ou seja, o controle sobre a identidade étnica a partir do controle do território.

As identidades indígenas tornam-se indissociáveis da territorialidade (OLIVEIRA, 2003; MURA, 2006), no sentido não meramente cartográfico, já que o lugar possui história, memória e se mistura com o ser e o poder (NASCIMENTO, 2016). Assim, as disputas nos processos de demarcações de terras demonstram o caráter colonialista contemporâneo da sociedade nacional frente a autonomia étnico/cultural indígena. Ao manter a insegurança e o sentimento da impossibilidade de autogestão das suas terras de vínculo ancestral, a lógica da dominação persiste contra os povos indígenas.

Por este aspecto, a discriminação social na apropriação dos benefícios do dinamismo econômico é o traço dominante na sociedade brasileira, que é uma das poucas economias no mundo cuja parcela de $10 \%$ mais ricos controla mais de 50\% da renda nacional" (BECKER \& EGLER, 1994, p. 22). Essa discriminação afeta toda a estrutura social, provocando implicações aos direitos culturais de maneira profunda, impedindo ou dificultando com que os povos indígenas atuem ou exerçam em plenitude seu modo ser, de viver e de fazer, de maneira autodeterminada. Significa entender que houve a reatualização das práticas motivadas na questão étnica que anula outras expressões culturais plurais. Neste aspecto, cria embaraços constantes ao 
direito de cada povo viver nos seus próprios termos, ou seja, de vivenciar em plenitude a sua cultura, segundo teoricamente a concebe (GEERTZ, 2008).

\section{Considerações Finais}

Immanuel Wallerstein defendeu a tese que, desde sua origem no século XVI, o Sistema Mundo produziu desigualdades estruturais entre as regiões de trocas comerciais, tendo sido a América Latina a primeira periferia da Europa. Para a América Latina e o Caribe, a emergência do Sistema Mundo Moderno Colonial significou o início da primeira forma de domínio colonial europeu que criou as condições necessárias para aquilo que Aníbal Quijano (2000) chamou de colonialidade do poder. O século XVI configurou alguns aspectos do padrão de poder que influenciariam não apenas 0 comportamento social, político e econômico como também cultural.

De acordo com a teoria do Sistema Mundo, o norte do planeta se afirma a partir do século XV como centro capaz de acumular riquezas e criar tecnologias, enquanto as zonas periféricas surgem como espaços a serem explorados, supridores de mão de obra e recursos naturais para os centros hegemônicos. Isso significou, entre outras determinações, a definição na América Latina de estruturas sociais em que a subordinação indígena aos interesses do poder colonial foi uma condição necessária para a acumulação sistêmica da riqueza na metrópole europeia. Ou seja, o lugar dos povos indígenas no Sistema Mundo Moderno/Colonial foi desde cedo definido como um lugar de subordinação via escravidão, trabalho compulsório ou extermínio para ocupação de suas terras.

Nos últimos anos, as violências contra os povos indígenas passaram a ser denunciadas nos foros internacionais (BELLIER, 2013). Ilustrativamente, cita-se a Conferência Internacional sobre a discriminação dos Povos Indígenas nas Américas que aconteceu em Genebra em setembro de 1977 e contou com a participação de representantes indígenas de 15 países do continente americano. Na Resolução Final da Conferência os representantes dos povos indígenas declararam como tem imperado a discriminação, o genocídio e o etnocídio e mostraram que, mesmo considerando as variações de país a país, as violências coloniais e póscoloniais foram brutais e semelhantes para todos eles (STAVENHAGEN, 1988, p. 181).

Alguns anos mais tarde, em 1981, outra Conferência Internacional das Nações Unidas sobre Povos Indígenas e a Terra aconteceu. Participaram dessa conferência cento e trinta representantes indígenas procedentes de 
diferentes países do mundo. Na declaração final, mais uma vez, violências comuns são denunciadas, especialmente, o saque das terras e de seus recursos naturais (STAVENHAGEN, 1988, p. 182).

No quadro do sistema da Organização das Nações Unidas (ONU), as denúncias sobre as violações dos direitos humanos dos povos indígenas são apresentadas à Comissão de Direitos Humanos, à UNESCO e a OIT. Desde 1982 foi constituído o Grupo de Trabalho sobre Populações Indígenas que faz parte da Subcomissão para a Prevenção da Discriminação e a Proteção das Minorias da mesma Comissão de Direitos Humanos. É para esse Grupo de Trabalho que os representantes indígenas de diversas partes do mundo têm encaminhado suas denúncias de violações de seus direitos.

O fato dos povos indígenas de todo mundo terem vivenciado experiências semelhantes de violações de seus direitos mostra que o que lhes acontece é sobredeterminado pelas dinâmicas do Sistema Mundo Moderno/Colonial. Mesmo que suas experiências assumam formas próprias de acordo com cada contexto nacional, é notável o fato de que suas denúncias sejam tão coincidentes.

A análise histórica das violências contra os povos indígenas em sua relação com as lógicas do Sistema Mundo Moderno/Colonial demonstra que, em uma dimensão interna, as formas de violências são, ao mesmo tempo, fator de construção e produto de relações sociais desiguais entre os grupos, controladas e regulamentadas pelos aparelhos legislativo, judiciário, administrativo e militar e pelas ideologias dominantes. Mas elas também podem ser relacionadas, em um contexto de Sistema Mundo, a uma dimensão externa capaz de revelar as relações econômicas e políticas desiguais entre centro e periferia. As duas dimensões, interna e externa, dessas violências não são independentes, já que uma funciona como um derivado ou uma legitimação da outra.

No caso do Brasil, a elaboração de um relato breve sobre as violências cometidas contra os povos indígenas se defronta com a triste dificuldade de um excesso de material, conforme constatado por Junqueira e Paiva. É difícil identificar os fatos mais graves, considerando que a própria história de constituição do Estado brasileiro, de sua unificação territorial e de seu controle político, se assenta sobre a dominação e o extermínio desses povos (JUNQUEIRA E PAIVA, 1988, p. 223).

A situação dos povos indígenas do Brasil hoje continua sendo amplamente determinada por sua experiência colonial e pelas formas que ela assumiu nos períodos subsequentes. A história das violências cometidas contra os povos indígenas no Brasil revela a continuidade de algumas práticas, 
dispositivos, discursos e valores, construídos ao longo desses mais de 500 anos de relações entre índios e brancos. Além disso, revela muitas ambiguidades e contradições como, por exemplo, o reconhecimento dos direitos dos índios em relação às próprias terras e a garantia da proteção de suas especificidades culturais, sociais e políticas não foram respeitados. $O$ resultado dessas experiências e a constatação de que os povos indígenas se encontram, hoje, em uma situação de grande fragilidade no Brasil demonstram que eles ainda vivem sob influência das estruturas coloniais (latifúndio e poder das oligarquias locais) e da ideologia positivista (tutelaproteção), dotadas de suportes políticos e jurídicos importantes.

O contexto atual de crise política, institucional, financeira e ideológica se apresenta como um dos períodos mais complexos da história do país. Nesse contexto, os povos indígenas do Brasil se defrontam com uma série de ameaças às garantias constitucionais, de retrocessos em termos de políticas e de direitos e de violências contra as comunidades e lideranças (YAMADA, 2017, p. 6). O último Relatório "Violência contra os povos indígenas do Brasil" produzido pelo Conselho Indigenista Missionário (CIMI, 2017) com os dados de 2016 e o Relatório da Relatoria de Direitos Humanos e Povos Indígenas da Plataforma de Direitos Humanos DHESCA Brasil de 2016 revelam um agravamento das violações de direitos humanos cometidas contra esses povos. Em ambos os Relatórios foi apontado 0 aumento do número de perseguições, das ameaças e de execuções de lideranças indígenas.

O momento atual, em quase duas décadas do século XXI, ante os ataques de reversão de direitos e das medidas estatais que criam embaraços incompatíveis com o pacto constituinte de 1988, os quais estão emoldurados na lógica econômica neoliberal agressiva, nos mostra a atualidade da proposta teórica do Wallerstein e da compatibilidade do pensamento decolonial para refletir e discutir as violências sobre os povos indígenas na contemporaneidade, na persistência das políticas de restrição de direitos e de anulação identitária, o que alude a inegável convicção de que presenciamos ainda a continuidade do processo moderno/colonial do etnocídio.

\section{Referências}

ARIENTI, Wagner Leal; FILOMENO, Felipe Amin. Economia política do moderno sistema mundial: as contribuições de Wallerstein, Braudel e Arrighi. Ensaios FEE, v. 28, n 1, Porto Alegre, 2007, pp. 99-126. Disponível em: $\quad<$ https://revistas.fee.tche.br/index.php/ensaios/article/view/2138>. Acesso em 10 nov. 2017. 
BARTH, F. "Os grupos étnicos e suas fronteiras (Introdução)". In: O guru, $o$ iniciador e outras variações antropológicas. Trad. John Cunha. Rio de Janeiro: Contracapa, 2000, pp. 25-67.

BECKER, Bertha K.; EGLER, Cláudio A. G. Brasil: uma nova potência regional na economia-mundo, $2^{\text {a }}$ ed., Rio de Janeiro: Bertrand Brasil, 1994.

BELLIER, Irène. "La reconnaissance internationale des peuples autochtones". In: BELLIER, Irène (dir.). Les Peuples Autochtones dans le monde. Les enjeux de la reconnaissance. Paris: L'Harmattan, 2013, pp. 13 38.

BRAUDEL, Fernand. La Méditerranée et le monde méditerranéen à l'époque de Philippe II. Paris: Armand Colin, 1949.

CAHEN, Michel. "Será a etnicidade culpada? As ciências sociais, a Jugoslávia, Angola e outros". In: GONÇALVEZ, António Custódio (ed.), África subsariana. Globalização e contextos locais. Porto: Faculdade de Letras da Universidade do Porto, 2002, pp. 93-104.

CARNEIRO DA CUNHA. M. "Política Indigenista no século XIX". In: História dos índios no Brasil. São Paulo: Companhia das Letras. Secretaria Municipal de Cultura, 1992, pp. 133-154.

CIMI. Relatório Violência contra os Povos Indígenas no Brasil. Dados de 2016. Brasília: Conselho Indigenista Missionário/CIMI, 2017. Disponível em: $<$ http://www.cimi.org.br/pub/Relatorio2016/relatorio2016.pdf $>$. Acesso em 22 dez. 2017.

CLASTRES, P. A sociedade contra o Estado. Tradução de Theo Santiago. São Paulo: Cosac Naify, 2003.

CLAVERO, B. Geografia jurídica da América Latina. México: Siglo XXI, 2008.

DUSSEL, Enrique. El encubrimiento del otro. Hacia el origen del "mito de la Modernidad". Colección Academia. La Paz: UMSA/Plural Editores, 1994.

GEERTZ, Clifford. A interpretação das Culturas. Rio de Janeiro: LTC, 2008.

JUNQUEIRA, Carmem; PAIVA, Eunice. La legislación brasileña y las poblaciones indígenas en Brasil. In: STAVENHAGEN, Rodolfo (dir.). Derecho indígena y derechos humanos en América Latina. Instituto Interamericano de Direitos Humanos, El Colégio de México, 1988, pp. 213-238. Disponível em: $<$ http://www.corteidh.or.cr/tablas/13089.pdf>. Acesso em 23 dez. 2017.

MARTÍNEZ-VEGA, Carlos A. The World Systems Theory. Research Seminar in Engineering Systems, Novembro, 2003. Disponível em: 
$<$ http://web.mit.edu/esd.83/www/notebook/WorldSystem.pdf $>$. Acesso em $21 \mathrm{dez} .2017$.

MIGNOLO, Walter. Historias locales/diseños globales. Colonialidad, conocimientos subalternos y pensamiento fronterizo, Madrid: Akal, 2003.

MURA, F. À procura do "bom viver": território, tradição de conhecimento e ecologia doméstica entre os Kaiowa. Tese de Doutorado, PPGAS, UFRJ/ MN, Rio de Janeiro, 2006.

NASCIMENTO, Sandra. Colonialidade do Poder no Direito e Povos Indígenas na América Latina: as faces da subordinação/dominação jurídica frente ao direito de retorno às terras ancestrais dos povos indígenas Kaiowá do Tekohá Laranjeira Nande'Rú no Brasil e Mapuche do Lof Temucuicui no Chile. Tese de Doutorado. Programa de Pós-graduação em Estudos Comparados sobre as Américas (PPG/CEPPAC) da Universidade de Brasília (UnB), 2016.

OLIVEIRA, Roberto Cardoso de. Sobre o pensamento antropológico. Rio de Janeiro: Tempo Brasileiro, 2003.

QUIJANO, Aníbal. Colonialidad del poder y clasificación social. Journal of World-Systems Research, Pittsburg, VI, 2, summer/fall 2000. Special Issue: Festchrift for Immanuel Wallerstein, Part 1, pp. 342-386. Disponível em: $<$ https://doi.org/10.5195/jwsr.2000.228>. Acesso em $21 \mathrm{dez} .2017$.

RESENDE, Ana Catarina Zema de. Direitos e autonomia indígena no Brasil (1960-2010): uma análise histórica à luz da teoria do sistema-mundo e do pensamento decolonial. Tese de Doutorado. Departamento de História. Instituto de Ciências Humanas, Universidade de Brasília, 2014.

RESTREPO, Eduardo e ROJAS, Axel. Inflexión decolonial: fuentes, conceptos y cuestionamentos. Popayán: Editorial Universidad de Cauca, 2010.

ROJAS, Carlos Antonio Aguirre. Immanuel Wallerstein y la perspectiva crítica del análisis de los sistemas-mundo. Revista Textos de Economia, v. 10, n. 2. Universidade Federal de Santa Catarina, Florianópolis, 2007, pp. 1157. Disponível em:<https://doi.org/10.5007/\%25x>. Acesso em 20 dez. 2017.

SANTOS, S. M. Ordem Jurídica e Identidade Nacional na Primeira República. Dissertação de Mestrado no Programa de Pós-Graduação em Direito da Universidade Federal de Santa Catarina, 2006. Disponível em $<$ http://repositorio.ufsc.br/xmlui/handle/123456789/88724>. Acesso em 10 dez. 2017. 
SILVA, Cristhian Teófilo da. "Identificação étnica, territorialização e fronteiras: a perenidade das identidades indígenas como objeto de investigação antropológica e a ação indigenista". Revista de Estudos e Pesquisas (Fundação Nacional do Índio), Brasília, v. 2, 2005, pp. 113-114. Disponível em: $<$ http://bit.ly/2BSsXdj $>$. Acesso em $11 \mathrm{dez} .2017$.

SILVA, Cristhian Teófilo da. "Entre o colonialismo perene e o multiculturalismo constitucional: Repensando os limites da descolonização e os desafios da autonomia indígena na América Latina", Brasília, 2012. Artigo apresentado no Seminário de comemoração dos 25 anos do CEPPAC - UnB.

SOUZA LIMA, Antonio Carlos de. "Sobre Indigenismo, autoritarismo e nacionalidade: considerações sobre a constituição do discurso e da prática da proteção fraternal no Brasil". In: OLIVEIRA FILHO, J. P. Sociedades indígenas e indigenismo no Brasil. Rio de Janeiro: Marco Zero, 1987.

STAVENHAGEN, Rodolfo. Derecho indígena y derechos humanos en América Latina. Ciudad de México: Instituto Interamericano de Derechos Humanos. El Colégio de México, 1988. Disponível em: $<$ http://www.corteidh.or.cr/tablas/13089.pdf $>$. Acesso em 23 dez. 2017.

WALLERSTEIN, Immanuel Maurice. Análisis de sistemas-mundo. Una Introducción. $2^{\mathrm{a}}$ ed. México: Siglo XXI editors, 2006.

El Moderno Sistema Mundial. La agricultura capitalista y los orígenes de la economia-mundo europea en el siglo XVI. México: Siglo Veintiuno Editores, 1979.

YAMADA, Erika. Relatório da Relatoria de Direitos Humanos e Povos Indígenas da Plataforma de Direitos Humanos DHESCA Brasil. Brasília: Terra de Direitos, 2017. Disponível em: <http://bit.ly/2LyVAfj>. Acesso em 21 dez. 2017. 